\title{
MATRIK
}

Jurnal Manajemen dan Teknik Industri-Produksi

Journal homepage: http://www.journal.umg.ac.id/index.php/matriks

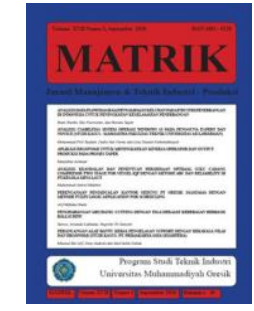

\section{Komoditas Unggulan Kluster Agroindustri Perkebunan Di Provinsi Sumatera Selatan}

\section{Hendrixon Hatta $^{1^{*}}$, Udisubakti Ciptomulyono ${ }^{2 *}$}

Program Studi Pascasarjana Magister Manajemen Teknologi Jurusan Manajemen Industri, Institut Teknologi Sepuluh Nopember

Jl. Cokroaminoto 12A, Surabaya, 60264, Jawa Timur, Indonesia hendrixonhatta@gmail.com ${ }^{1 *}$,udisubakti@ie.its.ac.id ${ }^{2 *}$

\begin{tabular}{l} 
INFO ARTIKEL \\
\hline $\begin{array}{l}\text { doi: } \mathbf{1 0 . 3 5 0 5 8 7 / M a t r i k} \\
\text { v18i2.589 }\end{array}$ \\
\hline Jejak Artikel : \\
Upload artikel \\
23 November 2019 \\
Revisi oleh reviewer \\
O8 Agustus 2020 \\
Publish \\
16 September 2020 \\
\hline
\end{tabular}

\section{Kata Kunci :}

Daya Saing, LQ,

DEMATEL, ANP
ABSTRAK

Provinsi Sumatera Selatan dalam proses penentuan kluster industri perkebunan berdasarkan komoditas unggulan daerah ini didasarkan kepada hasil dari musyawarah pihak pemerintah daerah tanpa adanya dukungan pendekatan edukasi yang dilakukan dalam penetapan tematik unggulan tersebut. Penentuan kluster industri ini dapat dijadikan arahan pembangunan daerah yang dapat mempermudah aktor inovasi daerah dalam mengambil langkah kebijakan strategis dalam memajukan daerah. Penelitian ini bertujuan menentukan komoditas dan produk unggulan daerah yang dilakukan dengan pendekatan draft akademik agar memiliki sifat diterima dan operasional. Dalam penelitian ini penentuan komoditas dan produk unggulan daerah dilakukan dengan pendekatan ilmiah menggunakan metode LQ dan Integrasi DEMATEL dan ANP. Hasil dari penelitian ini adalah kopi $(4,54)$, karet $(4,49)$ dan kelapa sawit $(4,45)$ produk unggulan prioritas daerah berbasis komoditas yang memiliki rantai nilai industri yang baik untuk dikembangkan oleh aktor inovasi dalam merumuskan kebijakan dan program untuk mendukung produk unggulan daerah tersebut agar memiliki daya saing secara nasional maupun global. 


\section{Pendahuluan}

Proses penentuan kelompok industri berbasis komoditas di daerah didasarkan pada hasil musyawarah pemerintah daerah tanpa dukungan pendekatan pendidikan yang dilakukan dalam menentukan fitur tematik. Pengembangan klaster industri dapat digunakan sebagai area pendukung yang dapat memfasilitasi pengembangan aktor inovasi regional dalam mengambil langkah dalam memajukan area kebijakan strategis. Dokumen arah kebijakan sistem inovasi nasional RPJPN 2010-2025 dan 2005-2025 mengarahkan bahwa dalam mentransformasikan ekonomi yang didasarkan pada keunggulan komparatif ekonomi berbasis sumber daya alam menjadi keunggulan kompetitif, harus dilakukan dengan prinsip-prinsip dasar pengelolaan peningkatan produktivitas nasional melalui inovasi (BAPPENAS, 2005). Ini membutuhkan perspektif dan bertindak secara sistemik dan sistematis dalam Sistem Inovasi Nasional (SIN) (BPPT, 2012). Konsep hubungan aliran pengetahuan dinamis triple helix antara tiga aktor inovasi yaitu U - Universitas, I - Industri, dan $\mathrm{G}$ - Pemerintah sebagai institusi pemangku kepentingan yang mendukung keberhasilan sistem inovasi (Henry Etzkowitz, 2008). Proses penentuan kelompok industri berbasis komoditas di daerah didasarkan pada hasil musyawarah pemerintah daerah tanpa dukungan pendekatan pendidikan yang dilakukan dalam menentukan fitur tematik. Pengembangan klaster industri dapat digunakan sebagai area pendaratan yang dapat memfasilitasi pengembangan aktor inovasi regional dalam mengambil langkah dalam memajukan area kebijakan strategis.

Penelitian ini bertujuan untuk menentukan area unggulan komoditas dilakukan dengan pendekatan akademik rancangan agar memiliki properti dan operasi yang dapat diterima (Ciptomulyono, 2010). Pengambilan keputusan MCDM adalah metode keputusan proses pemilihan alternatif mempertimbangkan dengan kriteria obyektif atau lebih dari orang yang berada dalam situasi yang bertentangan (bertentangan). Menurut (Masudin \& Ayni, 2018) pendekatan MCDM membuat pilihan karena kemampuan metode ini dalam pengambilan keputusan dalam pemilihan jika prosesnya lebih dari satu pengambil keputusan dimana setiap keputusan memiliki konflik antara kriteria atau tujuan dalam pemilihan produk unggulan (Sidjabat, Filson Maratur dan Runtuk, 2019). Hybrid MCDM digunakan dalam menghadapi permasalahan pengambilan keputusan yang kompleks, yang umumnya terdiri atas faktor kualitatif dan kuantitatif. Hybrid MCDM digunakan sebagai kombinasi dari beberapa metode dalam pengambilan keputusan (Masudin \& Ayni, 2018). Terdapat berbagai metode yang digunakan dalam mengevaluasi kriteria-kriteria pemilihan, seperti data envelopment analysis (DEA) (Wu, 2009), heuristic (Herawati dkk, 2009), analytic hierarchy process (AHP) (Sevkli dkk, 2007), fuzzy goal programming (Kumar dkk, 2006), hingga analytic network process (Lin, 2009); (Togatorop \& Soanderia, 2017). Metode pemilihan kriteria ini seringkali dikombinasikan dengan metode lainnya seperti DEMATEL. Metode DEMATEL digunakan untuk mengetahui hubungan saling ketergantungan (relasi mutual) antar kriteria dan derajat ketergantungannya (Cahyadi \& Anna, 2017). Salah satu metode MCDM yang digunakan dalam tulisan ini adalah ANP (Analytical Network Process) (Herly, 2017); (Waskito, 2017). Metode ANP menggunakan 10 responden ahli yang mewakili triple helix. Penelitian ini bertujuan untuk menentukan prioritas komoditas unggulan menjadi produk unggulan yang dipilih dalam rangka penguatan SIDA di Provinsi Sumatera Selatan.

Konsep triple helix ini merupakan hubungan aliran pengetahuan yang dinamis antara ketiga aktor inovasi yaitu $U$-Universitas, $I$ - Industry, and $G-$ Government sebagai lembaga pemangku kepentingan yang mendukung keberhasilan dari sistem inovasi (Henry Etzkowitz, 2008).

Metode LQ dapat melihat kepadatan sektor usaha tertentu pada suatu wilayah dibandingkan dengan sektor yang sama secara agregat. Dalam prakteknya, pendekatan LQ meluas tidak terbatas pada bahasan ekonomi saja akan tetapi juga dimanfaatkan untuk menentukan sebaran komoditas atau melakukan identifikasi wilayah berdasarkan potensinya (Hendayana, 2003). Pendekatan ini relevan dalam menentukan 
komoditas ditinjau dari segi penawaran yaitu produksi. Untuk komoditas berbasis lahan maka perhitungan didasarkan pada areal lahan, produksi, dan produktivitas. Sedangkan untuk komoditas non-lahan seperti perikanan tangkap dan peternakan dapat digunakan populasi atau produksi.

DEMATEL diaplikasikan untuk menggambarkan hubungan keterkaitan antar kriteria dan menentukan kriteria utama yang mendominasi kriteria lainnya. Metode ini mendesain sebuah struktur sistem dengan menggunakan pengetahuan dari ahli (Vujanovic dkk, 2012). Penggunaan DEMATEL disebabkan oleh beberapa alasan antara lain: metode ini dapat memperlihatkan hubungan antar kriteria dengan grafik dan juga angka, tingkat kepentingan (bobot) dari kriteria tidak hanya ditentukan oleh kriteria yang berhubungan langsung (upstream atau downstream) namun keseluruhan kriteria (Herdiawan et al., 2020).

ANP merupakan suatu cara penilaian untuk mengukur skala rasio prioritas dari faktor-faktor yang berpengaruh dalam keputusan. Metode ini merupakan pengembangan dari metode AHP (Analytical Hierarchy Process). ANP diperkenalkan oleh Saaty (2000) dengan tujuan untuk menyelesaikan permasalahan ketergantungan dan umpan balik (feedback) antar kriteria dan alternatif di dunia nyata. ANP mampu menyelesaikan secara sistematis semua jenis ketergantungan antar kriteria. ANP menjadi metodologi yang mudah diaplikasikan untuk studi kualitatif yang beragam, seperti pengambilan keputusan, forecasting, evaluasi, mapping, penyusunan strategi, ataupun alokasi sumber daya. Keterkaitan pada metode ANP terdiri dari keterkaitan dalam satu set elemen (inner dependence) dan keterkaitan antar elemen (outer dependence) (Pambudi, 2018); (Rusydiana \& Hasib, 2019).

\section{Metode Penelitian}

Metodologi Penelitian Penelitian ini membutuhkan literatur tentang konsep sistem inovasi, agenda strategis penguatan sistem inovasi daerah, konsep klaster industri, agroindustri, pengambilan keputusan multikriteria (Dematel dan ANP), dan review literatur terdahulu. Pada tahap persiapan observasi tidak dilakukan secara langsung ke lapangan, melainkan hanya mengkaji data statistik yang diperoleh dari badan pusat statistik (BPS) tentang kondisi daerah amatan dan panduan pengembangan klaster industri dalam konteks sistem inovasi daerah. Penentuan sampel dilakukan dengan cara purposive sample dikarenakan keterbatasan waktu dan biaya penelitian. Penelitian menentukan responden ahli sebanyak 10 (sepuluh) orang yang mewakili unsur triple helix.

\section{Hasil dan Pembahasan}

Metode LQ dapat melihat kepadatan sektor usaha tertentu pada suatu wilayah dibandingkan dengan sektor yang sama secara agregat. Dalam prakteknya, pendekatan LQ meluas tidak terbatas pada bahasan ekonomi saja akan tetapi juga dimanfaatkan untuk menentukan sebaran komoditas atau melakukan identifikasi wilayah berdasarkan potensi daerahnya (Hendayana, 2003); (Hatta \& Nursanty, 2020). Pendekatan ini relevan dalam menentukan komoditas ditinjau dari segi penawaran yaitu produksi. Untuk komoditas berbasis lahan maka perhitungan didasarkan pada areal lahan, produksi, dan produktivitas. Sedangkan untuk komoditas non-lahan seperti perikanan tangkap dan peternakan dapat digunakan populasi atau produksi.

Metode LQ dapat menggunakan data beberapa tahun perhitungan. Persamaan yang digunakan:

$$
\mathrm{LQ}=q_{i} q_{d} Q_{i} Q_{r}
$$

Keterangan:

$\mathrm{q}_{\mathrm{i}}=$ produksi total komoditas i di daerah

$\mathrm{q}_{\mathrm{d}}=$ produksi total subsektor di daerah

$\mathrm{Q}_{\mathrm{i}}=$ produksi total komoditas $\mathrm{i}$ di wilayah referensi (propinsi)

$\mathrm{Q}_{\mathrm{r}}=$ produksi total subsektor di wilayah referensi (propinsi) 
Nilai LQ yang lebih besar dari 1 (satu) menunjukkan bahwa suatu komoditas di daerah tersebut memiliki tingkat produksi yang lebih baik dari rata-rata daerah lainnya dan dapat diistilahkan berswasembada. Komoditas inilah yang layak menjadi alternatif komoditas unggulan.

Dari hasil LQ diperoleh delapan komoditas berpotensi unggul yang mewakili kelima subsektor agroindustri. Kedelapan komoditas ini berada pada tingkat swasembada pada saat ini (lihat tabel 1).

Tabel 1. Perhitungan LQ Komoditas Unggulan Agroindustri Sumsel

\begin{tabular}{|l|l|}
\hline No. & Komoditas Unggulan Sumsel \\
\hline 1. & Aren \\
\hline 2. & Coklat \\
\hline 3. & Cengkeh \\
\hline 4. & Gambir \\
\hline 5. & Holtikultura \\
\hline 6. & Kayu Manis \\
\hline 7. & Karet \\
\hline 8. & Kapuk \\
\hline 9. & Kemiri \\
\hline 10. & Kehutanan \\
\hline 11. & Kelapa \\
\hline 12. & Kelapa Sawit \\
\hline 13. & Kopi \\
\hline 14. & Lada \\
\hline 15. & Nilam \\
\hline 16. & Padi \\
\hline 17. & Panili \\
\hline 18. & Pinang \\
\hline 19. & Perikanan \\
\hline 20. & Peternakan \\
\hline 21. & Tanaman Sayur \\
\hline 22. & Tebu \\
\hline 23. & Tembakau \\
\hline Sumber : Hasil Pengolahan Data
\end{tabular}

Pada penelitian ini menggunakan kriteria yang digunakan pada penelitian komoditi unggulan daerah (Kementrian Perindustrian, 2013) karena sesuai dengan tujuan penelitian yang dilakukan dan mengakomodir kebutuhan penilaian komoditas unggulan dalam kerangka penguatan SIDa di Provinsi Sumatera Selatan. Pada penelitian ini terdiri dari 7 kriteria utama yaitu bahan baku, sumber daya manusia, akses pemasaran, infrastruktur, teknologi dan inovasi, modal sosial dan kelembagaan, serta kontribusi terhadap perekonomian (lihat tabel 2).

DEMATEL diaplikasikan untuk menggambarkan hubungan keterkaitan antar kriteria dan menentukan kriteria utama yang mendominasi kriteria lainnya. Metode ini mendesain sebuah struktur sistem dengan menggunakan pengetahuan dari ahli (Shih dkk, 2010); (Sidjabat, Filson Maratur dan Runtuk, 2019). Penggunaan DEMATEL disebabkan oleh beberapa alasan dapat memperlihatkan hubungan antar kriteria dengan grafik dan juga angka, tingkat kepentingan (bobot) dari kriteria tidak hanya ditentukan oleh kriteria yang berhubungan langsung (upstream atau downstream) namun keseluruhan kriteria (Fadlulloh \& Mu'tamar, 2019).

Tabel 2. Matriks Hubungan Total Tc

\begin{tabular}{|l|l|l|}
\hline No. & Kriteria & Bahan Baku \\
\hline 1. & Bahan Baku & 1 \\
\hline 2. & Sumber Daya Manusia & 2,6 \\
\hline 3. & Akses Pemasaran & 0,8 \\
\hline 4. & Infrastruktur & 0,5 \\
\hline 5. & Teknologi dan Inovasi & 1,3 \\
\hline 6. & $\begin{array}{l}\text { Modal Sosial dan } \\
\text { Kelembagaan }\end{array}$ & 3,2 \\
\hline 7. & $\begin{array}{l}\text { Kontribusi terhadap } \\
\text { perekonomian }\end{array}$ & 2,3 \\
\hline
\end{tabular}

ANP merupakan suatu cara penilaian untuk mengukur skala rasio prioritas dari faktor-faktor yang berpengaruh dalam keputusan (Destari, 2016). Metode ini merupakan pengembangan dari metode AHP (Analytical Hierarchy Process). ANP diperkenalkan oleh Saaty (1996) dengan tujuan untuk menyelesaikan permasalahan ketergantungan dan umpan balik (feedback) antar kriteria dan alternatif di dunia nyata. ANP mampu menyelesaikan secara sistematis semua jenis ketergantungan antar kriteria. ANP menjadi metodologi yang mudah diaplikasikan untuk studi kualitatif yang beragam, seperti pengambilan keputusan, forecasting, evaluasi, mapping, penyusunan strategi, ataupun alokasi sumber daya (Cahyadi, 2019). Keterkaitan pada metode ANP terdiri dari keterkaitan dalam satu set elemen (inner dependence) dan keterkaitan antar elemen (outer dependence) (Pambudi, 2018); (Rusydiana \& Hasib, 2019). ANP seringkali dikombinasikan dengan DEMATEL atau lebih dikenal dengan DANP. Tujuannnya untuk mempermudah proses penilaian dan efisiensi waktu. Masukan dalam ANP adalah matriks hubungan total $(\mathrm{Tc})$ yang diperoleh dari proses DEMATEL.

1. Membangun unweighted supermatriks $\mathrm{W}=(\mathrm{T} c \propto) 1$

$\mathrm{T} c \propto=\mathrm{k} . \mathrm{Tc}$

$\mathrm{k}=\min 1 \operatorname{maxi} t i j n j=1,1 \operatorname{maxj} t i j$

$n i=1$, 


$$
i, j=1,2, \ldots, \mathrm{n}
$$

2. Membuat matriks $\mathrm{T}^{D} \propto$ yang merupakan matriks normalisasi dari matriks TD. Matriks TD adalah matriks dimensi (set atau kumpulan kriteria).

3. Membuat matriks weighted supermatriks

$\mathrm{W}^{\alpha}=\mathrm{T}^{D}{ }_{\alpha} \mathrm{x} \mathrm{W}$ (perkalian elemen)

4. Membuat matrik stabil (stable-matriks) dari weighted supermatriks dengan menjadikan limit $g \rightarrow \infty$ limit $\left(W^{\alpha}\right)^{g}$. Matriks ini merupakan matriks bobot untuk setiap kriteria.

Penelitian ini diperoleh dari hasil dari penilaian yang dilakukan 10 orang responden ahli yang terdiri dari 4 orang dari unsur pemerintah, 3 orang akademisi dan 3 orang dari dunia usaha kemudian dilakukan pengolahan data (lihat tabel 3).

Tabel 3. Kriteria Pemilihan dan Bobot ANP

\begin{tabular}{|l|l|l|}
\hline No. & Kriteria & Bobot \\
\hline 1. & Bahan Baku & 0,147 \\
\hline 2. & Sumber Daya Manusia & 0,135 \\
\hline 3. & Akses Pemasaran & 0,180 \\
\hline 4. & Infrastruktur & 0,213 \\
\hline 5. & Teknologi dan Inovasi dan & 0,144 \\
\hline 6. & $\begin{array}{l}\text { Modal Sosial } \\
\text { Kelembagaan }\end{array}$ & 0,075 \\
\hline 7. & $\begin{array}{l}\text { Kontribusi terhadap } \\
\text { perekonomian }\end{array}$ & 0,107 \\
\hline \multicolumn{2}{|l|}{ Sumber : Hasil Pengolahan Data } \\
\hline
\end{tabular}

Dari hasil penilaian bobot ANP diperoleh bahwa kriteria infrastruktur memiliki bobot tertinggi dengan nilai 0,213 dan bobot terendah 0,075 dimiliki kriteria modal sosial dan kelembagaan. Ini berarti kriteria infrastruktur mempengaruhi 6 (enam) kriteria lainnya yang digunakan dalam penelitian sehingga dapat menjadi prioritas dalam intervensi pengembangan SIDa di Provinsi Sumatera Selatan.

Dari hasil bobot ini dilakukan pengisian kuesioner 10 (sepuluh) orang responden ahli yang digunakan untuk menentukan 9 (sembilan) prioritas komoditas unggulan di Provinsi Sumatera Selatan (lihat tabel 4).

Tabel 4. Prioritas Komoditas Unggulan SIDa di Sumatera Selatan

\begin{tabular}{|l|l|l|}
\hline Peringkat & Komoditas SIDa & Index \\
\hline 1 & Kopi & 4,54 \\
\hline 2 & Karet & 4,49 \\
\hline 3 & Kelapa Sawit & 4,45 \\
\hline 4 & Holtikultura & 4,26 \\
\hline 5 & Kelapa & 4,11 \\
\hline 6 & Sayuran & 4,08 \\
\hline 7 & Panili & 4,07 \\
\hline
\end{tabular}

\begin{tabular}{|l|l|l|}
\hline 8 & Gambir & 4,04 \\
\hline 9 & Perikanan & 4,00 \\
\hline \multicolumn{2}{|l|}{ Sumber : Hasil Pengolahan Data } \\
\hline
\end{tabular}

Komoditas yang terpilih menjadi prioritas adalah Kopi, Karet dan Kelapa Sawit. Selain komoditas tersebut untuk komoditas holtikultura, kelapa, sayuran, panili, gambir dan perikanan tetap menjadi pilihan prioritas dari pengembangan komoditas berbasis SIDa yaitu sesuai dengan karakteristik dan potensi daerah dalam upaya pengembangan komoditas tersebut.

\section{Kesimpulan dan Saran}

Prioritas komoditas unggulan berbasis SIDa di Provinsi Sumatera Selatan yang diperoleh dalam penelitian ini adalah Kopi $(4,54)$, Karet $(4,49)$, dan Kelapa Sawit $(4,45)$ dengan kriteria utama adalah pembenahan dalam infrastruktur untuk mendukung pengembangan komoditas unggulan tersebut.

Komoditas kopi dan karet ini dikelola lebih dari $70 \%$ oleh rakyat Sumatera Selatan sedangkan untuk komoditas kelapa sawit dikelola oleh sektor swasta lokal maupun swasta nasional. Pengembangan komoditas kopi dan karet ini harus dilakukan multi sektoral agar implikasi yang dihasilkan akan lebih terukur dan berkesinambungan.

Penulis menyarankan agar Pemerintah Provinsi Sumatera Selatan dan Pemerintah Daerah Kabupaten/Kota diharapkan dapat bersinergi dalam memenuhi rantai pasok dalam pengembangan komoditas unggulan kopi, karet dan kelapa sawit. Setiap komoditas tersebut bahan baku diolah terlebih dahulu untuk mendapatkan nilai tambah yang lebih sehingga dijual tidak hanya dalam bentuk bahan baku.

\section{Daftar Pustaka}

Artana, K.B (2008), "Pengambilan Keputusan Kriteria Jamak (MCDM) Untuk Pemilhan Lokasi Floating Storage And Regalitification Unit (FSRU) : Studi Kasus Supply LNG Dari Ladang Tangguh Ke Bali”, Jurnal Teknik Industri, Vol. 10, No.2, Hl 97-111.

Ankrah, Samuel., Al-Tabbaa, Omar., (2015), "Universities-Industry Collaboration: A 
systemic review", Scandinavian Journal of Management (31), page 387-408.

BAPPENAS, (2005), “ Dokumen Rencana Pembangunan Jangka Panjang 2005-2025 (RPJP). Badan Perencanaan Pembangunan Nasional: Jakarta.

BPPT, (2000), "Pohon Industri Inovasi Teknologi”, BPPT Press, Jakarta.

BPPT, Tim., (2012), "Naskah Akademik Buku Putih Penguatan Sistem Inovasi Nasional", Deputi Bidang Pengkajian Kebijakan Teknologi BPPT: Jakarta.

BPS, Tim., (2015), "Sumsel Dalam Angka", Badan Pusat Statistika Provinsi Sumatera Selatan: Sumatera Selatan.

BALITBANGNOVDA, Tim., (2012), "Buku Saku Profil Litbang Daerah", Badan Penelitian Pengembangan dan Inovasi Daerah Prov. Sumsel: Sumsel.

Cahyadi, I. (2019). Developing A Model with Dematel, ANP, Topsis Approaches for Marketing Strategy Selection in Batik Madura Industry. Matrik: Jurnal Manajemen, Strategi Bisnis Dan Kewirausahaan, $\quad 14(1), \quad 20$. https://doi.org/10.24843/matrik:jmbk.20 20.v14.i01.p03

Cahyadi, I., \& Anna, I. D. (2017). Penentuan Strategi Pemasaran Batik Madura Dengan Pendekatan Multi Criteria Decicion Making. Journal Industrial Servicess, 3(1), 185-190.

Ciptomulyono, Udisubakti., (2000), "Integrasi Metode Dhelpi dan Prosedur Analisis Hirarki (AHP) untuk Identifikasi dan Penetapan Prioritas Objektif/Kriteria Keputusan". Journal IPTEK, Vol.7.

Ciptomulyono, U. (2010). Paradigma Pengambilan Keputusan Multikriteria dalam Perspektif Pengembangan Projek dan Industri yang Berwawasan Lingkungan, Pidato Pengukuhan untuk Jabatan Guru Besar dalam Bidang Ilmu Pengambilan Keputusan Multikriteria pada Jurusan Teknik Industri, Fakultas Teknolologi Industri, Institut Teknologi Sepuluh Nopember Surabaya.

Destari, R. A. (2016). Sistem Rangking Pemanfaatan Susu Bayi Menggunakan Analytical Network Process (ANP).
Sisfotenika, $\quad 6(1), \quad 56-67$. https://doi.org/10.30700/jst.v6i1.105

Fadlulloh, K., \& Mu'tamar, M. F. F. (2019). Pemilihan Alternatif Pemasok Beras Industri Catering Menggunakan Analytical Network Process (Studi Kasus di PT . AXC). Agroindustrial Technology Journal, 03(01), 1-10.

Hatta, H., \& Nursanty. (2020). Penentuan Produktivitas Daerah Kabupaten Terbaik Sebagai Penghasil Tanaman Sayuran Cabai Di Provinsi Sumatera Selatan Menggunakan Diagram Kartesius. Publikasi Penelitian Terapan Dan Kebijakan, 3(1), 26-33.

Henry Etzkowitz, 2008, "The Triple Helix: University-Industry-Government

Innovation in Action", Routledge, New York. Hendayana, Rahmat (2003), "Aplikasi Metode Location Quotient (LQ) dalam Penentuan Komoditas Unggulan Nasional", Informatika Pertanian No. 12, hal. 1-17.

Herawati, C.T., (2010), "Perencanaan Strategis Industri Jasa Perawatan \& Perbaikan Kendaraan Bermotor Untuk Menerapkan Manajemen Green Company Dengan Pendekatan MCDM-AHP Dan Analisa SWOT", Tesis, MMT ITS Surabaya.

Herdiawan, D., Ahmadi, \& Wibowo, H. (2020). Penentuan kriteria dan strategi dalam menghadapi peperangan kepulauan dengan pendekatan dematel ANP. Rekayasa : Journal of Science and Technology, 13(1), 1-14.

Herly, K. (2017). Usulan Pemilihan Supplier Produk Rice Cooker Di Toko Dapur Mutiara Dengan Metode Analytical Network Process.Skripsi.

Masudin, I., \& Ayni, M. G. F. (2018). Pengambilan Keputusan Multi Kriteria: Kajian Teoritis Metode dan Pendekatan Dalam Pemilihan Pemasok. Jurnal Ilmiah Teknik Industri, 17(1), 1. https://doi.org/10.23917/jiti.v17i1.538

Kramer, Jan-Philipp., Marinelli, Elisabetta., Lammarino, Simona., Diez, Revilla, Javier., (2011), "Intagible assets as drivers of innovation:Emperical evidence on multinational enterprise in German and UK 
regional systems of innovation", Journal Technovation (31), page 447-458.

Kravtsova, V dan Radosevic, S. (2012), "Are Systems of Innovation in Europe Efficient?", Economic Systems, No. 36, hal. 109-126.

Liao, Shu-Hsien., Wu, Chi-chuan., (2010), "System perspective of knowledge management, organizational learning, and organizational innovation", Journal of Expert System with Applications (37), page 1096-1103.

Lin, R.-H. (2009), “An Integrated FANPMOLP for Supplier Evaluation and Order Allocation", Applied Mathematical Modelling, No. 33, hal. 2730-2736.

Pambudi, A. S. (2018). Pemilihan Engineering Contractor Proyek Dana Hibah Energi Terbarukan Dengan Metode Dematel Dan Anp. Bisma, 12(2), 145.

https://doi.org/10.19184/bisma.v12i2.78 78

Perindustrian, Kementrian., (2013), "Kajian Pengembangan Kompetensi Inti Industri di Wilayah III (Kawasan Papua dan Maluku)", Laporan Penelitian, Jakarta.

Porter, Michael., (1994), "Competitive Advantage (Keunggulan Bersaing)”, Edisi Bahasa Indonesia, Binarupa aksara, Jakarta.

Puspita, F. Niniek, 2014, "Pengembangan SIDa Provinsi Jawa Timur", LPPM ITS, Surabaya

Rangkuti., Freddy (2002), "Analisa SWOT Teknik Membedah Kasus Bisnis, Reorientasi Konsep Perencanaan Strategis Untuk Menghadapai Abad 21", PT. Gramedia Pustaka Utama.

Riset dan Teknologi, Kementrian., (2014), "Panduan Penguatan Sistem Inovasi Daerah (SIDa)", Deputi Bidang Jaringan IPTEK: Jakarta.

Rusydiana, A. S., \& Hasib, F. F. (2019). Islamic Banking Selection Criteria: Case in Indonesia Using Analytic Network Process. Economica: Jurnal Ekonomi Islam, $\quad 10(1), \quad 165$. https://doi.org/10.21580/economica.201 9.10.1.2846

Saaty, T.L., (2000), "Fundamental Of Decision Making \& Priority Theory With Analytical
Hierarchy Process (AHP)'”. Pittsburg: RWS Publications.

Sidjabat, Filson Maratur dan Runtuk, J. K. (2019). Pengembangan Model Pemilihan Green Supplier. Journal of Environment Engineering \& Waste Management, 4(1), 9-20.

Togatorop, \& Soanderia, T. (2017). Pengukuran Kinerja Supplier dengan Menggunakan Metode DEMATEL dan ANP di PT. Barata Indonesia (Persero) Medan.Skripsi

Vujanovic dkk. (2012), "Evaluation of Vehicle Fleet Maintenance Management Indicators by Application of DEMATEL and ANP", Expert Systems with Applications, No. 39, hal. 10552-10563.

Waskito, A. D. (2017). Alternatif Pemilihan Supplier Pita Sarung Tangan Golf Dengan Menggunakan Metode ANP (Studi Kasus Di CV.Sarung Tangan Pamungkas).Skripsi

Wang, Y.L. Dan Tzeng, G.H. (2012), "Brand Marketing for Creating Brand Value Based on A MCDM Model Combining DEMATEL with ANP and VIKOR Methods", Expert Systems with Applications, No. 39, hal. 5600-5615. 
Hendrixon $^{1^{*}}$ \& Ciptomulyono ${ }^{2 *} /$ MATRIK. Vol.XXI, No.1, September 2020, Halaman 1-8

(Halaman ini sengaja dikosongkan) 